\title{
Reading Dynamic Patterns of Silence as a Communication Strategy and Impediment in the EFL Classroom Interaction
}

\section{Eka Fadilah}

Post Graduate Student of English Education and Teaching, Universitas Negeri Malang, Indonesia,mref3k4@gmail.com

\section{Utami Widiati}

Universitas Negeri Malang, Indonesia, utami.widiati.fs@um.ac.id

\section{Mohammad Adnan Latief}

Universitas Negeri Malang, Indonesia, a.adnanlatief@gmail.com

\begin{abstract}
This study aimed to investigate the dynamic patterns of two concepts of silence explicated as a communication strategy and impediment in a task-based instruction. A novel approach, Retrodictive Qualitative Modeling (RQM) tied in a Dynamic System Theory (DST), was utilized to identify learners' archetypes, to highlight the dynamic patterns underlying their silence, and to unveil the factors affecting the two concepts as dynamic signatures. Of eighteen learners of English department, we took three participants relying on their salient archetypes. Those participants were nominated based on the Focus Group Discussion (FGD) encompassing three lecturers. Furthermore, a stimulated recall interview was carried out on the three participants to get overarching factors affecting their silence. The results revealed twofold: (1) the participants' dynamic patterns of classroom trajectory explicating the variability of elements underlying the learners' silence vary across the learners' archetypes, (2) signature dynamics modeled manifest and distinguish the two concepts of silence. The implication of this study entails the EFL lecturers to have a background knowledge in distinguishing the two concepts of silence that encompass dynamic and fluctuative signature dynamics of motivation, cognition, English proficiency, positive and negative emotions interacting with the classroom contexts. Likewise, further study might provide more overarching factors underlying those two concepts of silence to provide a finer-grained result delineating such concepts.
\end{abstract}

Keywords: silence, classroom interaction, retrodictive qualitative modeling, communication strategy, EFL

Citation: Fadilah, E., Widiati, U., \& Latief, M. A. (2019). Reading Dynamic Patterns of Silence as a Communication Strategy and Impediment in the EFL Classroom Interaction. International Journal of Instruction, 12(4), 183-200. https://doi.org/10.29333/iji.2019.12412a 


\section{INTRODUCTION}

The growing body of research reports on silence has refuted the allegation of stereotypes (e.g., reticence, total obedience to authority, passivity, less critical thinking) to Asian learners as certain cultural attributes (see e.g., Choi, 2015; Harumi, 2011; Shao \& Gao, 2016; Kumaravadevalu, 2003; Ghavamnia \& Ketabi, 2015; Yashimaet al., 2016; Zhou et al.,, 2005). Instead, Kumaravadevalu (2003, p. 710) argues that such stereotypes are alleged to be merely, 'more imagination of Western Academia than in the actual classrooms of Asian societies'. Furthermore, Kumaravadevalu criticizes the excessive use of discourse on cultural stereotypes overlooking L2 classroom characteristics which are not solely skewed across Asian learners. Indeed, such alleged stereotypes are shared and experienced by all learners studying a Foreign or Second Language (F/SL). Nakane's (2006) investigation on Japanese and Australian learners revealed that both groups shared the same interpretation of silence strategy: to maintain a positive face (e.g., Avoiding loss of face, anticipating negative perception from lecturers), to avoid the FTA (Face Threatening Act), and to speak unless requested to comment (off-record strategy). Along the same lines, King and Aono's (2017) quasi-experimental study on Japanese and UK learners revealed that both groups shared a similar experience of silence that is the feelings of situational anxiety, nervousness, and confusion during classroom interaction.

In line with Kumaravadevalu's claim, Yashima et al. (2016) argues that those alleged stereotypes are 'groundless' when assigned to Japanese EFL college learners' characteristics. The extant studies have not garnered adequate evidence to verify these allegations. Anchored in Complex Dynamic Systems Theory (CDST), Yashima et al. 's observation on Japanese learners unveiled that the learners' proclivity for talk or silence is affected by the individual factors and characteristics which interconnect to the classroom contexts (e.g., teachers' support, topic familiarity, classroom atmosphere). Interestingly, none of their findings explicates cultural stereotypes as the causes of learners' talks or silence. In a similar vein, Zhou et al. (2005) asserted such cultural attributes as "a myth" based on their findings of Chinese learners studying at Canadian universities. They revealed that the Chinese learners' silence denotes a strategy in avoiding discomfort associated with disagreement and maintaining harmonious relationships resulting from Chinese learners' custom of "didactic and teacher centered style of teaching" rooted in "Confucian pedagogies" (p. 288). Likewise, Shao and Gao (2016) synthesized ten research articles unraveling factors underlying East Asian learners' reticence and Willingness to Communicate (WtC) published from 2000 to 2015. They revealed factors underlying reticence and $\mathrm{WtC}$ as correlation between various individual and contextual factors (i.e., history, social condition, process).

The considerable findings reveal that Asian learners' proclivity of silence carried out across Asian countries (e.g., Korea, Indonesia, Iran, Japan, Hongkong, China) delineates its complexity and silence is caused by multiple routes: motivational, cognitive, social, language proficient and emotional factors that interact with the environmental context (i.e., classroom environment), rather than the cultural stereotypes heavily attributed (see e.g., Choi, 2015; Fadilah, 2018; Ghavamnia \& Ketabi, 2015; Harumi, 2011; King, 2013; 
Tsui, 1996). For instance, Fadilah's (2018) investigation of eight Indonesian university learners revealed interrelated factors affecting the learners' Un/Willingness to Communicate $(\mathrm{U} / \mathrm{WtC})$ encompassing social and classroom contexts, features of linguistic competence, and affective factors. His finding refutes the cultural stereotypes addressed to a certain ethnic (i.e., Javanese) of Indonesian as 'total obedience, unquestioning mind, and the belief that the old know all as well as that the teacher can do no wrong' (Marcellino, 2008, p.58). Indeed, such stereotypes cannot be addressed overwhelmingly to a certain group of learners for every learner is 'not culturally conditioned to be silent and passive' (Shao \& Gao, 2016, p. 119).

\section{Complex Dynamic System and Silence}

Complex Dynamic System Theory (CDST) emerges as a new fashion in language learning. The former emphasizes on the interconnectedness of systems encompassing many interacting components or elements, while the latter signifies the changes from one state to another states in the individual trajectory (Larsen-Freeman \& Cameron, 2008; Thelen \& Smith). Thelen and Smith (1994) argued that studying individual trajectory drew our attention to the role of intra-individual variability and its fluctuation explicating the differences in the behavior within the same individuals at different points in time.

King (2013) has pioneered the utilization of CDST to investigate factors influencing Japanese learners' silence. The finding reveals that the learners' variability of silence is provoked by multiple concurrent variables in the classroom context (e.g., hypersensitivity to others, teacher-centered method, Lack of L2 ability, unfamiliarity with topics). Thus, silence is conceived as key attractor states/dynamic signatures - 'a stable place where the system settles, whatever its initial conditions and whatever path the system takes to reach equilibrium' (Thelen \& Smith, 1994, p.53). In his study, King reported silence as attractor states that emerged dynamically and nonlinearly along the path of the systems i.e., classroom activities which is influenced by the variability of learners' internal (e.g., individual differences) and external factors (e.g., classroom interactional contexts). Venturing into the same theory, King (2016) utilized a series of stimulated recall interviews to uncover a five-Japanese-learner's thoughts and feelings about silence. The finding revealed the underlying multiple, interconnected, and complex factors (i.e., the interplay between learners' internal and classroom environmental contexts) affecting learners' silence.

Smith and King (2018) pinpointed that the large body of research over-emphasizing on the necessity of 'verbal interaction' and 'oral production' on L2 acquisition has shaped the educators and researchers' image of learners' silence as 'largely negative phenomenon'. However, learners' absence such oral production in the entire conversation might not be conceived as limited participation, but rather adjusting their 'thought' to the relevant topic discussed. As such, the absence of verbal communication remains valid participation too (Bernales, 2016; Tatar, 2005).

The foregoing extant studies explicate the complex, dynamic, and multifaceted factors underlying L2 learners' silence. On the one hand, silence constitutes a challenge task that entails in-depth and more exploration (King, 2016). On the other hand, silence 
signifies an ambiguous phenomenon which might not only be skewed on the absence of oral communication, but rather as a part of communication (Bao, 2014; Karas 2016). Karas suggested distinguishing the construct or concept between silence and reticence due to their interchangeable use in a second/Foreign language research. For instance, Bernales (2016) elucidated the various constructs of silence drawn from Asian learners' context such as unwillingness to communicate, cultural norm, reluctance to speak, resistance to classroom participation, form of peripheral participation, and reticence. Although it is difficult to distinguish those overlapping concepts, it is important to differentiate the two in order to reduce student reticence, while still allowing space for silent learning (Bao, 2014). To Bao, the concept of silence and reticence is different in terms of its strategy. The former signifies intentional action as a part of communication strategy to enhance second language acquisition, while the latter denotes unintentional action impeding learners' second language acquisition caused by internal and external factors.

From the findings aforementioned, it is necessary to distinguish the learners' silence whether they persist to hold their silence as a communicative strategy or an impediment (i.e., reticence) concept that obscures their language performance. To best our knowledge, no previous studies clearly delineated the distinction of the two concepts. The overlapping use of the learners' silence has resulted in the bias addressed to a certain group of learner (e.g., Asian learners) as the passive and less critical-thinking (Shao \& Gao, 2016, Inter alia). Also, the focus of the learners' silence on EFL context is rarely discussed. Accordingly, this study endeavors to unveil the different constructs of silence emanated from the EFL learners (i.e., Indonesian) to provide finer-grained result of the two concepts of silence aforementioned.

\section{Research Aim}

Consulting Bao's and Karas' constructs for distinguishing silence and reticence, we conceive that those two constructs are the unique signature dynamics to be unraveled. Thus, this study aims at unveiling the system outcomes (i.e., learners' archetypes) and exploring the dynamic signatures that make the two constructs of silence unique. In order for the clarity, we label the former as "communication strategy", while the latter as "communication impediment" for convenience in this study. We portrayed the learner silence trajectory through an ecological lens i.e., task-based classroom instruction. Van Lier (2002) and King (2016) suggested taking this ecological approach to develop the moment-to-moment learner's behaviors by invoking close attention to the handling of unexpected occurrences in the classroom interaction. Accordingly, we endeavor to answer the following research questions:

(1) What do the learners' archetypes emerge and fit EFL learners' unique types?

(2) How do the various outcomes from a system trajectory manifest the unique dynamic signatures of silence as communication strategy or impediment?

\section{METHOD}

\section{Participants}

This research took place in an undergraduate English department program at a private university Surabaya, Indonesia. Eighteen EFL learners (ten male and eight female) in 
Year 2 (semester 4) participated in a task-based activity: Discussion. Their age ranged between 21 and 22. They have taken English skills courses in the previous semesters: Grammar (e.g., basic, intermediate), writing (e.g., descriptive, argumentative), speaking (e.g., daily conversation, academic talk), and listening (e.g., factual, effective).

Consulting Dornyei's (2014) RQM approach, we set up three steps in carrying out this research. First, identifying learners' archetypes i.e., salient learner types. We utilized qualitative-case approach by employing Focus Group Discussion (FGD) to elect the candidate of learners representing those archetypes (see e.g., Chan et al., 2015). Four lecturers were invited as informants along with their agreement to join the group discussion. Those lecturers have taught the participants since the first semester and been deemed to familiarize the participants characteristics. Second, electing participants that fit the established unique archetypes. Having formulated the learners' unique types, the first researcher asked the informants nominated the participants that fit those each levels. Third, modeling signature dynamics underlying the participants' silence. In this step, we mapped out the participants' dynamic systems with reference to the dynamic patterns of silence through the trajectory. Eventually, learners' silence factors signified as signature dynamics were construed and interpreted whether it signified communication strategy or impediment. A digital audio-record was utilized and transcribed that eventually translated into English by the first researcher for further analyses. Here, step one and two were designed to answer RQ 1, while step three was set up to elaborate RQ 2.

\section{Task Procedures}

The participants were asked to join a sixty-minute task-based classroom activity: problem-solving task. This task required them think critically with the regard to a topic entitled stranded in a desert. The participants were asked to solve a case as if they were stranded in a desert with a limited equipment to be chosen. They were asked to elect only five things (e.g., umbrella, knife, flare gun, a can of food) to survive in the desert. Furthermore, pair- and small group (4-5 members for each) discussed the things they needed to survive while waiting the aids from the other travelers. Lastly, every group presented their discussion in front of the other members. The other groups were allowed to make rebuttal, objection, and questions to the presenter.

\section{Data collection procedure}

A video-camera was posited with the best angle to record the learners' activity. Having executed the task activity, a Stimulated Recall Interview (SRI) was carried out immediately to the four nominated participants. Such an immediate interview enabled the high validity of the data collected in SRI (Gass and Mackey, 2000). The interview was taken in a quiet room lasted between 20 and 30 minutes for each participant conducted by the first researcher. The participants were freed to answer in Bahasa Indonesia or English to the questions proposed.

Following Gass and Mackey's (2000) protocol of SRI, the first researcher carried out both interactions i.e., instruction of the task and the recall. To Gass and Mackey, stimulus questions proposed during SR constitutes also constitutes the increase of validity in SRI. Some steps were taken during this recall process. First, the participants 
were introduced the aim of the interview by focusing on their silence in the task activity. Second, the video-record was played and paused in some parts indicating the participants' silence. The interviewer probed the participants' thought in parts of the video-record to be focused. The stimulus questions were proposed by pointing the paused-video record e.g., what were you thinking at this time?, you looked enthusiastic at this point, what were you thinking at this point?, you looked to be silent at this point, what were thinking? We strictly focused on a direct response of the participants related to what they were thinking of their silence based on the paused-video pointed by the interviewer. In other words, the response beyond 'what they were thinking then' explicating the participants' perception was excluded (see Gass \& Mackey, 2000 as the review). The interviewer asked the participants to provide a subsequent short response (e.g., I am shy, I am not confident) and elicitation to clarify their response.

\section{Data Analysis}

Following Chan et al. (2015) steps in carrying out RQM, we conducted a recursive and dynamic analysis for the data translated by reading every single words and utterances of the participants. Open and axial coding was carried out to search for tentative categories. We highlighted some important words, made notes, and subsequently generated ideas pertaining to keywords (e.g., attractor states) underlying silence. Those keywords were then grouped into two categories of silence as dynamic signatures i.e., as a strategy or impediment. Content analysis was then carried out by examining the possible interaction among those categories.

All participants' utterances from the interview were coded by using inter-rater agreement to measure the consistency. Two independent and trained lecturers assisted the first researcher in analyzing the transcript of the focal participants. First, we used the lists of emotional states (Izard, 2011) encompassing first order (e.g., joy, embarrassment, fear) and complex schemas (self-confidence, anxiety) as a compass for coding. Agreement between the first researcher and the two raters using Cohen's Kappa $(K)$ was at 0.88 and 0.94 respectively. When inter-rater agreement ranges between 0.85 and 0.90 , it is considered acceptable (Miles, Huberman, \& Saldana, 2014). Second, we brainstormed those codes to form the categories of silence (i.e., communication strategy and impediment). In this vein, we utilized Dynamic System Theory (DST, LarsenFreeman \& Cameron, 2008) to translate the possible changes and dynamic patterns of the learners' behaviors that emerge in the system trajectory (i.e., task activity).

\section{FINDINGS}

\section{Step One: Identifying Learners' Archetypes}

The first researcher, conducting the group discussion, provided lists of words identifying the Individual Differences (ID) of the learners: motivation, positive and negative emotions (e.g., self-confidence, anxiety), cognition (e.g., critical thinking), and English proficiency (e.g., the current scores in Year 2). During discussion, we brainstormed the possible differences attached on the participants. Having discussed and brainstormed the learners' archetypes, we proposed some unique types of the learners as follows: 
Perfect learner: The group saw this type as the learner with high internal and external motivation in addition for his/her high English proficiency. Such a learner has positive emotions (e.g., perseverance, creativity, self-confidence) in carrying out any tasks given. Also, this type has high critical thinking in solving the problems given.

Cheerful and motivated learner: The type of learner who has high level of motivation but average critical thinking in carrying out the tasks given. Despite his/her good ability in receptive skills (e.g., listening, reading), this learner often encounters anxiety and less confident in productive skill (e.g., speaking). This learner is portrayed to be obedient and creative by taking notes and looking the difficult words through dictionary during the lesson.

Motivated yet moody with sufficient English proficiency. This type of learner is portrayed to have sufficient English skills and motivation to engage in the classroom activity. However, this learner often encounters the emotional changes (i.e., happy to sad and vice versa) when interacting with his/her classmates. Also, this learner tends to avoid cooperating with the classmates and preferring to accomplish the task by him/herself.

Talk-active learner yet low English proficiency and low critical thinking. This type of learner shows the enthusiasm to participate in the classroom activity and confidence to raise his/her hand to ask any problems pertaining to the activity. However, this type of learner encounters the difficulty in understanding the lecturer's talk and has low content knowledge of the any topics discussed.

Less Motivated and low-average English proficiency but less creative learner: The lecturers opine this learner to have less internal motivation and low-average English proficiency. This type of learner is motivated when they have external forces (e.g., failure to pass a quiz) and dependency to the classmates. Although this type behaves well in the classroom activity, this learner type only does the assignments when the teacher asks them to accomplish.

Weak learner: this type is depicted as an unmotivated and low English proficient learner. His/her low critical thinking and high anxiety lead this type of learner to be 'good listener' during the classroom interactions. This learner is depicted to encounter difficulty to understand the lecturer's instructions.

\section{Step Two: Electing the Learners that Fit Each Archetype}

Although we could have elected any of the learners that fit the six archetypes proposed by the FGD, we select three participants (as the purpose of this study) nominated mostly by the lecturers (see Table 1). Those participants are categorized as (i.e., perfect, medium, weak) types. We then invited one participant from each level for further interview. Furthermore, those three participants (Jufri, Sinta, Asmo) anonymously were also asked to clarify their experiences during a task-based classroom to get thick information of their silence. 
Table 1

Learners' Archetypes based on the Participants' Interview

\begin{tabular}{|c|c|c|c|c|}
\hline $\begin{array}{l}\text { Interviewee } \\
\text { (pseudonym) }\end{array}$ & Motivation & Emotion & $\begin{array}{l}\text { Cognition and English } \\
\text { proficiency }\end{array}$ & Learners' quotes \\
\hline $\begin{array}{l}\text { Jufri } \\
\text { (Perfect } \\
\text { learner) }\end{array}$ & $\begin{array}{l}\text { High } \\
\text { internal and } \\
\text { external } \\
\text { motivation }\end{array}$ & $\begin{array}{l}\text { Talk-active and } \\
\text { confident to } \\
\text { propose opinion } \\
\text { during the } \\
\text { classroom } \\
\text { interactions } \\
\text { - Persevered learner }\end{array}$ & $\begin{array}{l}\text { - High-critical thinking } \\
\text { - High proficiency in } \\
\text { English skills: } \\
\text { speaking, writing, } \\
\text { grammar, and listening. }\end{array}$ & $\begin{array}{l}\text { 'I always try to enjoy } \\
\text { participating in the } \\
\text { classroom activities' } \\
\text { 'My parents want me to } \\
\text { study abroad. It is also } \\
\text { my dream' }\end{array}$ \\
\hline Sinta & $\begin{array}{l}\text { Motivated } \\
\text { and enjoy } \\
\text { studying } \\
\text { English }\end{array}$ & $\begin{array}{l}\text { less confident, fear } \\
\text { of making mistake } \\
\text { Less perseverance } \\
\text { Somewhat creative }\end{array}$ & $\begin{array}{l}\text { Low-medium critical } \\
\text { thinking } \\
\text { low English proficiency } \\
\text { in grammar, listening but } \\
\text { medium-high proficiency } \\
\text { in speaking and writing }\end{array}$ & $\begin{array}{l}\text { 'I like learning English } \\
\text { for my future jobs' } \\
\text { 'I am often not confident } \\
\text { to speak in English' }\end{array}$ \\
\hline $\begin{array}{l}\text { Asmo (Weak } \\
\text { learner) }\end{array}$ & $\begin{array}{l}\text { Less } \\
\text { motivated } \\
\text { learner }\end{array}$ & $\begin{array}{l}\text { High anxiety, no } \\
\text { self-confidence } \\
\text { moody, and solitary }\end{array}$ & $\begin{array}{l}\text { Uncritical } \\
\text { Low English proficiency }\end{array}$ & $\begin{array}{l}\text { 'My parents forced me to } \\
\text { learn English' } \\
\text { 'I often don't understand } \\
\text { at all the teacher's talk' }\end{array}$ \\
\hline
\end{tabular}

\section{Step Three: Modeling Signature Dynamics of Silence}

The ultimate goal of RQM is to build the understanding of how the complex causal mechanism involving individual or case leads to the particular outcomes (i.e., Signature dynamics) of which they are prototyped. As such, tracing back (i.e., retrodicting) the learners' trajectory constitutes the crucial stage. Having identified the initial steps (i.e., the archetypes and the learners that fit each archetype), we subsequently identify and set up signature dynamics of silence (i.e., communication strategy or impediment) associated with those initial prototypes. For the sake of the clarity and justification, the learners' thumbnail portrait and signature dynamics are elucidated.

Jufri

Jufri is a talk-active and open-minded learner. Additionally, he has a strong internal and external motivation to be able to speak English for his future careers and further study abroad. Also, his family strongly encourages him to be proficient in English. Excerpt 1 explicates a dialogue pertaining to his engagement in the parts of task activity (i.e., introduction, pair-large group discussion).

\section{Excerpt 1}

Interviewer: well ...you look to be enthusiastic at the beginning of the lesson, right? (pointing to the video-record).

Jufri: Yes sir...I like the way of the lecturer explains the lesson. I like the topic too. I am waiting for the next discussion.

Interviewer: But you were mostly silent in this group-discussion session. 
Jufri: Actually, I prefer pair-group discussion to large-group discussion. In pairs, I can freely give my full opinion with my classmate. But in large group, I am not comfortable, because I am not familiar enough with them.

Interviewer: Does it mean that you feel shy when talking not with your close friends?

Jufri: No. It is not like that. I am able to give my opinion. I want to practice my speaking in English, but the group mostly used Bahasa Indonesia to discuss the topic. I intentionally kept silent. One of my friends dominated group discussion. She speaks too much. Sometimes she didn't listen to the other opinion.

In Excerpt 1, Jufri expresses his interest and eagerness to engage in the classroom activity at the first twenty-minute of the lesson. However, he illustrates his annoyance (i.e., uncomforting situation) when encountering group discussion. The excessive use of Bahasa Indonesia, his friend's talk domination and ignoring the other members' opinion cause his annoyance and resistance in the group discussion. His intentional silence is affected by a situational factor (e.g., 4-5 group discussion) when encountering classmates who act like they know everything and discourage the others.

During twenty minutes of the classroom presentation and discussion session, he looked talking twice: proposing question for clarification and rebutting the presenter's argument. The rests, he retains silent. Excerpt 2 explicates his silence:

\section{Excerpt 2}

"Actually, I am not shy to give my opinion in front of the class. I am able to rebut my friend's arguments many times to show my disagreement... But I don't want to dominate the classroom discussion. I give opportunity for the others to share their opinion although I disagree with them"

From his comments, he expresses respecting the others and avoiding domination. He emphasizes that his silence is not caused by his shyness or no confidence when confirmed during the subsequent interview, but rather giving the others to talk and express their opinion. He further clarifies that he needs to use strategies (e.g., taking notes, arranging sentences) prior to talking. His silence is claimed for not to avoiding communication, besides he listens attentively to the others' opinions.

\section{Excerpt 3}

"I try to understand when the others speak. I am listening to them. Besides, I am accustomed to take notes prior to speaking; I need to arrange my sentences well before talking.

Tracing back his trajectory during the sixty-minute classroom activity, Jufri illustrates his dynamic patterns of his participation. He shows engagement in the first-twentyminute task activity. However, this condition tends to decline in the next ten-minute activity (i.e., group discussion) and somewhat increase during classroom presentation 
and discussion. In this vein, such dynamic patterns seem to be affected by some attractors (e.g., noticing, respecting to the others, annoyance) that interact with the classroom environment (e.g., teacher, classmates). Here, those attractors retain him to the condition called as attractor states i.e., silence. We model his silence explicating signature dynamics as the main discussion of this study as follows.

\section{Jufri's Signature dynamics}

Jufri's signature dynamics encompasses silence as communication strategy can be traced back of his classroom solidarity, creativity, noticing, and maintaining harmony, while silence as impediment can be traced back of his annoyance, anger, and alienation. The former can be translated that his silence signifies giving opportunity for the others to talk by avoiding talking too much during the discussion to maintain a classroom harmony. Additionally, his creativity in taking notes and listen to the others' talk attentively retain him to be silent. By contrast, the latter denotes his disengagement in a group discussion that results from group-member talk domination, uncomforting situation with the excessive use of L1, and less group member-rapport.

\section{Sinta}

Sinta is aware of the importance to speak up during the classroom activities. Her situational motivation fluctuates when encountering the classroom activity with regard to interesting and familiar topic, friendly lecturer, and group cohesiveness. During the first ten minutes in the introduction of the task activity, she shows her interest by commenting 'I like the topic. It is challenging. I also like the lecturer. He is very friendly and patient in explaining the lessons'. When pointed to her participation in the group discussion, she further comments 'I love working in pair and group discussions. I can learn English from other friends too'. However, when encountering the classroom presentation and discussion, her interest seems to decline. Excerpt 4 explicates her comments:

\section{Excerpt 4}

Interviewer: when you make presentation here, it looks that you do not respond the question from your friend immediately. What were you thinking at this point?

Sinta: mmm...I need to understand that question first. Afterward, I am thinking of my grammar and vocabulary to start speaking. I usually make notes before talking.

Interviewer: why don't you take notes to that question?

Sinta: I want to, but I don't have time. you know. In discussion we need to think quickly to answer (smiling)

Interviewer: Well. But you mostly keep silent in this classroom discussion. (pointing the video-recorded). 
Sinta: Yes, sir. Actually, I was eager to share my opinions. Sometimes I am jealous when my friend speaks English well. But I was shy and not confident.

Interviewer: Can you clarify about them: shy and not confident?

Sinta: I am afraid of my bad grammar and pronunciation. I am afraid of my friends' judgments on my English. I usually check the difficult words through my dictionary. But sometimes I ask my friends for such difficult words.

Interviewer: But you looked to raise your hand at this point? What were thinking about? (pointing to the video-record)

Sinta: I am thinking to answer the question and share my opinion, but when I want to initiate talk, my classmate has already talked.

In her presentation, Sinta expresses her silence-pause as a process of thinking prior to talk. As she is accustomed to making notes prior to talking, she confesses that she cannot respond any questions immediately. On the other hand, she illustrates that her silence is affected by multiple factors (i.e., embarrassment, low confidence, and nervousness) during the classroom discussion. Her feeling of lack English proficiency (e.g., grammar, pronunciation) seems to affect those factors. Interestingly, there is a shift from her silence as communication strategy to impediment. First, her strategy by writing down sentences prior to talking indicates her strategy to express her lack of ability, while her decision to speak after sentence formation explicates impediment resulted from less critical thinking that leads to less speed to initiate talk.

Excerpt 5 illustrates her disagreement with the other opinion but she is afraid of being judged to provide weak argument when rebutting the others' idea. This also indicates incertitude of her arguments. However, she still maintains her voiceless communication by listening attentively to the teacher or friends' opinion arguments provided to rebut or to objection to the other presenter.

\section{Excerpt 5}

"I sometime disagree with the presenter, but I cannot produce my words. I am afraid of my friends and lecturer opinion about my weak arguments. That's why, I prefer to wait for my friend and lecturer sharing their idea. I am very keen to get the answer. I don't need to share my idea, but I can learn from friends and lecturer"

Sinta's Signature Dynamics

Sinta's classroom trajectory explicates that she encounters multifaceted internalproclivity of her silence (i.e., negative emotions, cognition, and feeling of lack English proficiency). Such internal proclivities interact with the classroom environment: lecturer and classmates (e.g., negative judgment), teaching method (e.g., presentation, discussion). We model three dynamic signatures explicated this silence. First, her silence as impediment can be traced back of her feeling of lack English proficiency causes her to be shy and nervous to initiate talk. It also results in no confidence and embarrassment to communicate that eventually leads her to avoid talking (i.e., face- 
saving). Second, the communication strategy of her silence can be drawn from takingmaking notes, checking the difficult words through dictionary or asking them to her friends, listening attentively to the other ideas, and wait-time to make arguments. Third, her lack of speed reaction due to less critical thinking is modeled as transition from communication strategy to impediment

Asmo

$\mathrm{He}$ is a typical learner with low motivation and communication confidence. From the video-record, he mostly retains his silence during the classroom activity. When asked about his silence in the first-ten minute (i.e., introduction), he concedes "I have tried to understand the lecturer's talk, but I don't understand what he is talking about. I just remember a few words I am familiar with, I feel down".

During the group discussion, he looks involved some conversation with his pair next to him. When asked about that condition, he honestly confesses to discuss about things beyond the topic discussed by commenting 'we are just talking about my plans after the class (laughing)'. From the video-record, it is also depicted that he never takes and makes notes through the whole task activity. When confirmed about it, he further comments 'my friends have made notes for the discussion (smiling)'. His silence goes on in the classroom presentation. Excerpt 6 illustrates his comments when asked to elicit his silence.

\section{Excerpt 6}

'Yahh. I just keep silent all the time in that presentation. My English is not good and it makes me not confident. I try to listen when my lecturer and friends speak in English, but I often find difficulty to understand their talk. There are a lot of words that I don't understand. It often makes me frustration"

He acknowledges that he has no problems with his lecturer and classmates. To him, his silence is mostly caused by his incapability in English skills. Excerpt 7 illustrates her expression of silence during classroom discussion.

\section{Excerpt 7}

Interviewer: you look listening attentively in this discussion session. What are you thinking at this part? (Pointing to the video-record)

Asmo: I am afraid of being called on my name to answer the questions ...(laughing). I am not co

Interviewer: Is it your reasons by acting as if you listen to the presenter?

Asmo: Yes, it is one of the reasons ... (laughing). but I am listening to the others' opinion.

Interviewer: Do you understand their talk?

Asmo: No sir... (Laughing) .... I only memorize a few words. 


\section{Asmo's Signature Dynamics}

Unlike Jufri and Sinta's case, Asmo's silence is heavily caused by his difficulty in producing language output due to his lack ability in English skills. Such lack ability causes his low confidence and fear of being called on his name in answering questions. Also, his low topical knowledge and less creativity lead to avoid verbal communication (i.e., face saving). Having traced back his disengagement through the whole classroom activity, we model it as communication impediment.

\section{DISCUSSION}

\section{Learner Archetypes}

The categorization in the form of learners' prototypes (i.e., archetypes) explicates the variability of the behavioral elements underpinning a system. One of the tenet issues of this step is to confirm whether such archetypes exist in the lecturers' mind (Chan et al., 2015). The FGD has proposed six learner archetypes each varying in motivation, emotions, cognition, and English proficiency. Such categorization of learners' archetypes is reminiscent of Dornyei and Ryan's (2015, p.10, italic added) concept of three main mental types i.e., Trilogy of Mind - cognition, motivation, and affect (or emotions). As an integrated and dynamic system, such a trilogy manifests 'three mental dimensions that have continuous dynamic interaction with each other and cannot exist in isolation from one another' (p. 11). The other issue is whether the learners affirm such archetypes are firmly confirmed by the learners during the interview. However, it should be noted that the learners nominated by the lecturers does not always neatly fit the archetypes built up in FGD. It is likely affected by the different roles and perspectives between the learners and the lecturers in viewing such archetypes.

Jufri's dynamic trajectory of silence indicates the shift from one attractor state to another encompassing positive emotions (e.g., self-confidence, creativity in taking notes, interest), negative emotions (e.g., annoyance). Those attractor states seem to fluctuate when interacting with external elements of the system e.g., lecturer, topic, teaching method, group discussion. This confirms the previous findings explicating the dynamic and multiple factors affecting the learners' proclivity to talk or silence (see e.g., Bao, 2014; Bernales, 2016; Harumi, 2011). Additionally, he encounters perturbation (see e.g., Thelen \& Smith, 1994 as the main review) when engaging in the group discussion in which one of the group members dominates the talk and less respect to the others. This condition results in uncomfortable situation that retains him to be silent. By contrast, Asmo (i.e., a weak learner) illustrates his disengagement in sixty-minute taskbased interaction. His disengagement is mostly affected by his internal factors encompassing low motivation, negative emotions (e.g., anxiety, no self-confidence, shyness), cognition (less background of topical knowledge), and weak English proficiency (see e.g., Choi, 2015; Fadilah, 2018; King \& Aono, 2017). Indeed, those factors result in his silence through the whole class discussion.

On the other hand, Sinta encounters dynamic patterns (e.g., rise $\rightarrow$ decline) of her engagement in the classroom activity. In the initial condition, she seems to be enthusiastic to engage in the following activities due to the external factors (e.g., topic 
interest, friendly lecturer) that go on until the group discussion. However, when encountering classroom presentation and discussion, her engagement tends to decrease. This external factor (e.g., classroom environmental change) causes her emotional shifts from positive to negative ones (King, 2016). This phenomenon is called butterfly effect in which a small change may result in a huge impact (Larsen-Freeman \& Cameron, 2008). This study confirms the previous findings pertaining to the dynamic patterns of silence that are both linked one to another, changes over time, and forms a non-linear system (e.g., King, 2013; Smith \& King, 2018). The influence of external resources (i.e., classroom environment) affects such dynamics (e.g., Ghavamnia \& Ketabi, 2015; VanGeert, 2008). Also, this study supports the previous findings explicating internal and external factors affecting the learners' silence (e.g., Ghavamnia \& Ketabi, 2015; Harumi, 2011; Tsui, 1996).

\section{Signature Dynamics: Silence as Communication Strategy and Impediment}

Tracing back the data explicating moment-by-moment behavioral dynamics and variability in a developmental trajectory constitutes the essence of RQM to unravel the unique patterns of a system i.e., signature dynamics - a robust causal model in a system to unveil the main underlying dynamic patterns prototyped (Hiver, 2017).

Jufri's signature dynamics explicates his silence during as communication strategy and impediment. On the one hand, the former is manifested as 'politeness strategy' for classroom solidarity and maintaining harmony (Nakane, 2006; Reda, 2009; Zhou et al., 2005). However, he still listens attentively (i.e., noticing) to the others' comments. This finding supports the previous research reports (see e.g., Bernales, 2016; Tatar, 2005). Tatar (2005) argues that learners' silence is by no means a deviation of the standard form of participation but such a non-verbal communication remains mentally active in the classroom. Therefore, it is a valid communication too (Bernales, 2016). On the other hand, the latter manifests his silence affected by a situational factor (i.e., group discussion) arising his negative emotions (i.e., annoyance, anger, alienation). This less cohesiveness of group discussion makes him uncomfortable to speak (King, 2013; King \& Aono, 2017; Yashima et al., 2016).

The most unique case is found in Sinta's silence that embraces a three-dynamic signatures model manifested as communication strategy, impediment, and the shift from strategy to impediment. Like Jufri, her intentional silence by taking-making notes and noticing the lecturer's explanation and classmates' comments constitute her silence as communication strategy. Likewise, her strategy to check the vocabulary through dictionary and ask her friends when encountering the difficult words manifest her silence as communication strategy too, as Reda (2009, p.159) argues 'silence, then, can be a process of active engagement with the ideas of others' in which learners might have internal conversation with themselves that teachers cannot access. Her silence-pause prior to talk illustrates her strategy by formulating her declarative knowledge (e.g., sentence arrangement, vocabulary use) turned into procedural knowledge (e.g., using such linguistic appropriately) and eventually becomes automatized as an oral language (DeKeyser, 2007). On the other hand, her silence is also manifested as impediment resulting from her feeling of lacking English proficiency skills that leads to her negative 
emotions (e.g., Embarrassment, anxiety, and nervousness) and eventually retains her to save face and avoid verbal communication. This finding favors Choi's (2015) study that silence emerges as saving face caused by such emotional factors. That is, learning to speak is being vulnerable to criticism and judgment; and accordingly, it is safer to remain silent. One important thing that can be drawn from Sinta's case is a transitional shift from silence as communication strategy to impediment (Berger, 2004; Kurzon, 2007). Kurzon (2007) contends such a shift as "non-strategic in origin" by thinking to find the right words prior to talking (unintentional) which results in a decision not to speak until the right words come to mind (intentional). Her process of thinking to find the right words to speak is turned into a decision to be silent as a strategy due to her friend's interruption. In this vein, Berger (2004, p. 163) hypothesizes "the degree to which speechlessness is attributed to involuntarily causes is associated with emotional state, other than embarrassment and guilt".

Unlike Jufri's and Sinta's cases, Asmo's low participation is mostly masked by his handicap that results in communication impediments. His lack of linguistic competence and demotivation generate his lack of confidence to speak and eventually takes notable or conversational avoidance in communication (Bilmes, 1994).

\section{IMPLICATION AND CONCLUSION}

The findings thus far generally suggest factors underlying learners' dynamic patterns of silence portrayed in the classroom interaction. To our best knowledge, reading momentto-moment learners' silence either as the communication strategy or impediment concept delineates a novel approach explicated in this study. Dornyei and Ryan's (2015) Trilogy of Mind necessitates the interplay between the three mental types in shaping the learners' behaviors. However, those three types are insufficient to unravel the learners' silence in the classroom activity. This study provides the evidence that the lack of English proficiency heavily contributes the learners silence (i.e., as in Asmo's case). Additionally, such a proficiency interacts with the learners cognition, motivation, and emotions that retains the learners' silence (i.e., as in Jufri's and Sinta's case).

Additionally, this study provides the evidence to illuminate the fuzziness of the two concepts of silence. Bao (2014) rightly pointed out 'compared with knowledge of verbal communication, knowledge about silence remains minimal" (p. 18). As such, this study is aimed at providing the additional contribution in distinguishing the two constructs or concepts of silence to provide a finer-grained result of such concepts. It is urgently necessary to equip the EFL lecturers to distinguish such concepts. Also, further research might provide more overarching factors affecting those two concepts of silence. Accordingly, we propose recommendations for further research and pedagogical perspective. First, qualitative model invoking CDST needs to be echoed to unravel the other factors underlying both concepts. Gergersen (2007) argues that non-verbal communication (i.e., silence) is inevitably tied with emotions due to more innate tendency than verbal communication. However, emotions cannot be isolated from cognition as they interact one to another as complex schemas (Izard, 2011). Further study may provide more elaboration of the interplay between those two mental types interacting with the other internal and external contexts. Second, providing training for 
L2 teachers (e.g., pre-service, in service) in distinguishing both concepts need to be taken into consideration. For instance, they might be trained by employing various teaching strategy in treating the silence forms. Walsh (cited in Karas, 2016) proposes some categories to break learner's silence with questions to answer (e.g., open-floor, specific-student nomination, specific-student nomination in group discussion, studentstudent nomination).

In sum, we acknowledge that this study has some limitation. First, this study uses a small sample viewed in ecological perspective which may not be generalized to other contexts. Further study may take a representative sample with learners' various archetypes. Second, this study is only carried out in one task-based activity with 20-30 minuteinterview length only. Thereby, we cannot portray the overarching thumbnail portraits of the learners with reference to their signature dynamics underlying the two concepts of silence. Longitudinal study with various task activities might provide the overarching factors affecting the two concepts.

\section{REFERENCES}

Bao, D. (2014). Understanding silence and reticence: Ways of participating in second language acquisition. London: Bloomsbury.

Berger, C., R. (2004). Speechlessness: Causal attributions, emotional features and social consequences. Journal of Language and Social Psychology, 23(2), 147-179. https://doi.org/10.1177/0261927X04263821.

Bernales, C. (2016). Conflicting pathways to participation in the FL Classroom: L2 speech production vs. L2 thought processes. Foreign Language Annals, 42(2), 367-383. https://doi.org/10.1111/flan.12200.

Bilmes, J. (1994). Constituting silence: Life in the world of total meaning. Semiotica, 98(1/2), 73-87. https://doi.org/10.1515/semi.1994.98.1-2.73.

Chan, L., Dornyei, Z., \& Henry, A. (2015). Learner archetypes and signature dynamics in the language classroom: A retrodictive qualitative modelling approach to studying L2 motivation. In Z. Dornyei, P. D. MacIntyre, \& A. Henry (Eds.), Motivational dynamics in language learning (pp. 238-259). Bristol, UK: Multilingual Matters.

Choi, J., Y. (2015). Reasons for silence: A case study of two Korean students at a U.S. graduate school. TESOL Journal, 6(3), 579-596. https://doi.org/10.1002/tesj.209.

DeKeyser, R. (Ed.). (2007). Practicing in a second language: Perspectives from applied linguistics and cognitive psychology. New York, NY: Cambridge University Press.

Dörnyei, Z. \& Ryan, S. (2015). The psychology of the language learner - revisited. New York, NY: Routledge.

Dörnyei, Z. (2014). Researching complex dynamic systems: 'Retrodictive qualitative modeling' in the language classroom. Language Teaching 47(1), 80-91. https://doi.org/10.1017/S0261444811000516 
Fadilah, E. (2018). Willingness to communicate from Indonesian learners' perspective: A dynamic complex systems perspective. Journal of ELT Research, 3(2), 168-185. https://doi.org/10.22236/JER_Vol3Issue2pp168-185.

Ghavamnia, M. \& Ketabi, S. (2015). Voices from the voiceless: Iranian EFL students' attitudes toward English. Innovation in Language Learning and Teaching, 9(2), 102114. https://doi.org/10.1080/17501229.2013.849708.

Gregersen, T. (2007). Breaking the code of silence: A study of teachers' non-verbal decoding accuracy of foreign language anxiety. Language Teaching Research, 11(2), 209-221. https://doi.org/10.1177/1362168807074607.

Harumi, S. (2011). Classroom silence: Voices from Japanese EFL learners. ELT Journal, 65(3), 260-269. https://doi.org/10.1093/elt/ccq046.

Hiver, P. (2017). Tracing the signature dynamics of language teacher immunity: A retrodictive qualitative modeling study. The Modern Language Journal, 101(4), 669690. https://doi.org/10.1111/modl.12433.

Izard, C. (2011). Forms and functions of emotions: Matters of emotion-cognition interactions. Emotion Review, 371-378. https://doi.org/10.1177/1754073911410737.

Karas, M. (2016). Turn-taking and silent learning during open class discussions. ELT Journal, 7(1), https://doi.org/13-23. 10.1093/elt/ccw051.

King, J. \& Aono, A. (2017). Talk, silence and anxiety during one-to-one tutorials: A cross-cultural comparative study of Japan and UK undergraduates' tolerance of silence. Asia Pacific Educational Review, 18, 489-499. https://doi.org/10.1007/s12564-0179503-8.

King, J. (2013). Silence in the second language classrooms of Japanese universities. Applied Linguistics, 34(3), 325-343. https://doi.org/10.1093/applin/ams043.

King, J. (2016). Classroom silence and the dynamic interplay between context and the language learner: A stimulated recall study. In J. King (Eds.), The dynamic interplay between context and the language learner (pp. 127-150). Basingstoke: Palgrave Macmillan.

Kumaravadivelu, B. (2003). Problematizing cultural stereotypes in TESOL. TESOL Quarterly, 37(4), 709-719. https://doi.org/10.2307/3588219.

Kurzon, D. (2007). Towards a typology of silence. Journal of Pragmatics, 39, 16731688. https://doi.org/10.1016/j.pragma.2007.07.003.

Larsen-Freeman, D. \&Cameron, L. (2008) complex systems and applied linguistics. Oxford: Oxford University Press

Marcellino, M. (2008). English language teaching in Indonesia: a continuous challenge in education and cultural diversity. TEFLIN Journal, 19(1), 57-69. http://dx.doi.org/10.15639/teflinjournal.v19i1/57-69. 
Miles, M. B., Huberman, A. M., \& Saldana, J. (2014). Qualitative data analysis: A methods sourcebook. California: SAGE.

Nakane, I. (2006). Silence and politeness in intercultural communication in university seminars. Journal of Pragmatics,38(11), 1811-35. https://doi.org/10.1016/j.pragma.2006.01.005.

Reda, M. M. (2009). Between speaking and silence: A study of quiet students. New York, NY: Suny Press.

Shao, Q., \& Gao, X. A. (2016). Reticence and willingness to communicate (WTC) of East Asian language learners. System, 63, 115-120. https://doi.org/10.1016/j.system.2016.10.001.

Smith, L., \& King, J. (2018). Silence in the foreign language classroom: The emotional changes for L2 teachers. In J. de D. Martinez Agudo (Eds.), Emotions in second language teaching (pp.323-339). Springer: Springer International Publishing.

Tatar, S. (2005). Why keeps silent? The classroom participation experiences of nonnative-English-speaking students. Language and Intercultural Communication, 5(3-4), 284-293. https://doi.org/10.1080/14708470508668902.

Thelen, E., \& Smith, L. B. (1994). A dynamic systems approach to the development of cognition and action. Cambridge, MA: MIT Press.

Tsui, A. (1996). Reticence and anxiety in second language learning. In K.M. Bailey \& D. Nunan (Eds.), Voices from the language classroom: Qualitative research in second language education (pp. 145-167). Cambridge, UK: Cambridge University Press.

Van Geert, P. (2008). The dynamic systems approach in the study of L1 and L2 acquisition: An introduction. Modern Language Journal, 92, 179-199. https://doi.org/10.1111/j.1540-4781.2008.00713.x.

Van Lier, L. (2002). An ecological-semiotic perspective on language and linguistics. In C. Kramsch (Eds.), Language acquisition and language socialization: Ecological perspective (pp. 140-164). London: Continuum.

Yashima, T., Ikeda, M., \& Nakahira, S. (2016). Talk and silence in an EFL classroom: Interplay of learners and context. In J. King (Eds.), The dynamic interplay between context and the language learners (pp. 104-126). London: Palgrave Macmillan.

Zhou, Y. R., Knote, D., \& Sakamoto, I. (2005). Rethinking silence in the classroom: Chinese students' experiences of sharing indigenous knowledge. International Journal of Inclusive Education, 9, 287-311. https://doi.org/10.1080/13603110500075180. 